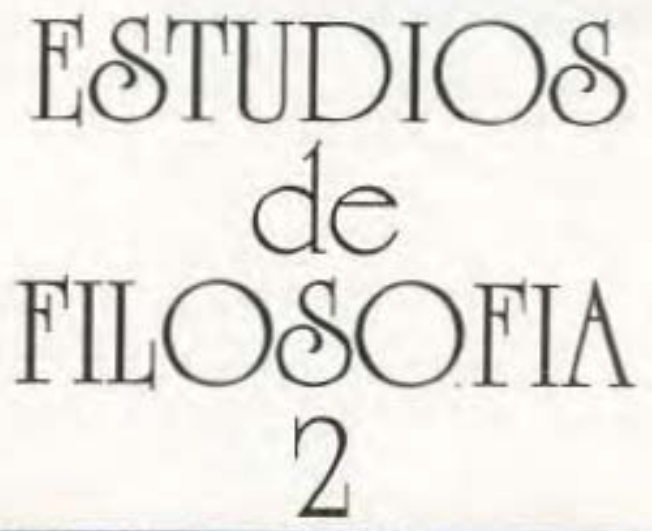




\section{MORALIDAD Y ETICIDAD}

El seminario estuvo dedicado al análisis y discusión de diferentes posiciones del debate filosófico contemporáneo sobre la moral. El hilo conductor de las discusiones fue la controversia entre las concepciones éticas que se agrupan hoy en día bajo los términos de moralidad y eticidad.

Siguiendo una distinción terminológica que se remonta a Hegel, se suele agrupar bajo el concepto de moralidad a todas aquellas concepciones éticas que, valiéndose de argumentos trascendentales, contractualistas, utilitaristas o discursivos, prosiguen en la actualidad la empresa deontológica inaugurada por Kant en sus escritos morales. El término eticidad, por su parte, es empleado para caracterizar a las posiciones éticas que pretenden reactualizar, ya sea la concepción hegeliana del 'espíritu objetivo', o la concepción aristotélica de la praxis, a la cual se remite explícitamente Hegel como fuente de inspiración. Si bien es cierto que estos términos pueden prestarse a equívocos o anacronismos, y pese a que no todos los interlocutores del debate se refieren a ellos explícitamente, hay buenas razones para considerarlos ya representativos de una discusión que se viene prolongando desde hace varios años y que no parece aún hallar solución.

Con el propósito de delimitar el sentido en que se emplean dichos términos como puntos de referencia de la tradición de la filosofía práctica, el seminario se inició con una discusión sobre las concepciones éticas de Aristóteles, Kant y Hegel. Se revisaron los modelos éticos propuestos por ellos, a fin de poder examinar luego con más precisión en qué medida resultan legítimos o adecuados los diversos modos de su reactualización.

A continuación, se seleccionaron obras significativas del debate mencionado, eva- luando en cada paso la peculiaridad de la propuesta y su eventual contribución al esclarecimiento de la pregunta sistemática del seminario. Las obras analizadas fueron: G.E. Moore, Principia ethica; H.-O. Apel, Transformación de la filosofia; J. Habermas, Teoría de la acción comunicativa; J. Rawls, Teoría de la justicia; A. MacIntyre, After Virtue. A Study in Moral Theory; Ch. Larmore, Patterns of moral complexity; P. Ricoeur, El discurso de la acción; R. Alvayay, C. Ruiz (compiladores), Democracia y participación.

En un sentido sólo aproximativo, puede decirse que, de los autores analizados, Rawls, Apel, Habermas y Larmore defienden posiciones cercanas al modelo de la moralidad, mientras que Moore, MacIntyre, Ricoeur y Taylor (en el volumen Democracia y participación) se identifican más con elementos propios del modelo de la eticidad -sin que esto signifique, por supuesto, que no existan discrepancias importantes en el interior de cada uno de estos grupos. La Teoría de la justicia de Rawls constituye ya una obra clásica en esta discusión, a la cual se refieren polémicamente, aun reconociendo su valor, todos los autores posteriores. Su posición es, en parte, una reactualización del imperativo categórico kantiano, así como de la idea del 'observador imparcial' de A.Smith, pero es también original en la medida en que reemplaza la argumentación trascendental por un tratamiento lógico-matemático del problema de la justicia. La 'imparcialidad' ('fairness') se realizaría, de acuerdo a su modelo, únicamente en aquella situación que procura mayores expectativas de beneficio a los menos favorecidos, como condición del beneficio de todos. Aun siendo muy sutil y sugerente, la argumentación de Rawls no logra satisfacer una de sus propias exigencias básicas, a 
saber: ofrecer una deducción necesaria de esta idea de la justicia. El reconocimiento de esta debilidad -no el objetivo último de reactua-lizar el imperativo kantiano- es lo que lleva a los otros autores mencionados a buscar formas más persuasivas de fundamentar una norma universal. Apel y Habermas comparten, en tal sentido, la convicción de que la obligatoriedad y la normatividad éticas deben ser buscadas en una teoría de la argumentación. Al margen de sus diferencias, ambos coinciden en un enfoque lingüístico-pragmático que indaga por las presuntas condiciones universales que todos los interlocutores hacen valer por el hecho mismo de intervenir en la comunicación argumentativa. Siguen aspirando pues a una demostración de la universalidad de la norma moral, pero consideran que la demostración no puede ser lógica, sino sólo pragmática. Larmore, por su parte, toma distancia de estos afanes deductivistas, pues piensa que en ningún caso logran superar los escollos de sus detractores. Su libro, presentado como una defensa contemporánea de la ética liberal, distingue, al igual que los anteriores, las cuestiones evaluativas de las normativas, es decir, separa el ámbito subjetivo de los sistemas de valores del problema de la coexistencia entre dichos sistemas. Pero este último problema es, para él, de carácter exclusivamente político, y no debería ser tratado bajo las condiciones de una demostración lógica. No obstante, buscando él también una forma de validar un principio universal, encuentra serias dificultades para culminar exitosamente su proyecto.

Por otra parte, si algo hay en común en el grupo de los autores vinculados el modelo de la eticidad, es justamente su rechazo de la concepción deontológica de la moral presente en los anteriores. En diferentes formas, todos ellos adoptan una perspectiva inmanente a los agentes éticos mismos, y no admiten la legitimidad de un modelo que, por principio, parece condenado a desconocer la racionalidad de la praxis. Moore, sin ser en sentido estricto un interlocutor en este debate, propone un acceso a la problemática moral bastante representativo, en la medida en que da prioridad al uso que hacemos de nuestras expresiones valorativas. Su "emotivismo" puede parecer quizás una simplificación del problema, pero es sin duda consecuente con la perspectiva analítica adoptada. El libro de MacIntyre, por su parte, es también ya un clásico de la discusión que comentamos, pues se trata del más serio intento por reactualizar la ética aristotélica en la sociedad moderna. Su punto de partida es un diagnóstico sobre el desorden del discurso moral en nuestra sociedad, cuyas causas han de ser buscadas a través de una reconstrucción histórica de los fragmentos o nociones éticas que coexisten en la actualidad. Al remontarnos a los orígenes griegos de nuestra moral -entre los cuales MacIntyre destaca, quizás excesivamente, la ética aristotélica-, podremos entender las razones que condujeron a la fragmentación y el desorden de valores éticos que nos caracterizan. En consecuencia, habría que replantear la moral asumiendo la riqueza conceptual del modelo aristotélico: podremos así, en su opinión, recuperar una visión unitaria de las virtudes morales, así como el carácter narrativo de nuestras percepciones valorativas. Aunque no explícito, hay un cierto hegelianismo en este uso que MacIntyre hace de la ética de Aristóteles. Taylor se adhiere en gran parte a las tesis de MacIntyre, que coinciden con su visión hermeneútica de la historia de la ética, pero no comparte la propuesta de un retorno al modelo de la Antigüedad. Sin embargo, más que una discrepancia de principio, lo que los distingue es un énfasis diferente en los elementos de que se compone el universo ético de la modernidad. Finalmente, el texto analizado de Ricoeur es un esfuerzo interesante por establecer un vínculo entre los esquemas categoriales de la interpretación analítica de la acción y el modo de vida que les sirve de sustrato -que, para Ricoeur, es teóricamente accesible gracias a los recursos conceptuales brindados por la fenomenología.

El análisis de estos textos no tuvo por finalidad zanjar el debate entre moralidad y eticidad, sino más bien permitir el acceso a su modus operandi, tratando de captar el sentido de sus preguntas y examinando la validez de sus soluciones. 


\section{BIBLIOGRAFIA}

Moore, G.E. Principia Ethica, México: U.N.A.M., 1959 .

Apel, K.O. Transformación de la Filosofía, Madrid: Taurus, $2 v$.

Williams, B. Ethics and the Limits of Philosophy, Cambridge: Harvard University Press, 1985.

Rawls, J. Teoría de la justicia, México: F.C.E., 1979.

Habermas, J. Teoría de la acción comunicativa, Madrid: Taurus, 1987.2v.

Macintyre, A. Tras la virtud. Barcelona: Ed. Crítica, 1987.
Larmore, Ch. Patterns of moral complexity, Cambridge: Cambridge University Press, 1987.

Ricouer, P. El discurso de la acción, Madrid: Cátedra, 1981.

Alvayay, R. y Ruiz, C. (comp.) Democracia y participación, Santiago: C.E.R.C., 1988.

\section{PARTICIPANTES}

Richard Celis, Pablo Quintanilla, Soledad Escalante, Víctor Samuel Rivera, María del Pilar González, Oscar Trelles, Kathia Hanza, Brenilda López.

\section{SEMINARIO SOBRE TEMAS DE IISTORIA DE LA FILOSOFIA CONTEMPORANEA}

\section{EL LUGAR Y EL ALCANCE DE LA PINTURA Y DEL DIBUJO EN EL MARCO DE LA DECONSTRUCCION}

"No existe nada que deteste y aborresca tanto como esa idea de espectáculo, de representación, luego de virtualidad y de no realidad, apegada a todo cuanto se produce y se exhibe".

\section{Antonin ARTAUD}

\section{I. "Transtornar el Subyectil"}

Las conjugadas nociones del Lugar y del Alcance pretenden promover aquí una forma inédita y potente de cuestionar la misma naturaleza de la (no) experiencia que nos proporcionan la pintura y el dibujo, apuntando para un (no) espacio y un (no) tiempo específicos de los (no) objetos pintados y/o dibujados, que no son en absoluto el espacio, el tiempo, y los objetos de nuestra experiencia perceptiva consciente de serdiciente tal como fue diseñada de un modo globalmente fenomenológico, por KANT o por HUSSERL por ejemplo.
Así pues se propone que se llame Subyectil al soporte de la pintura o del dibujo, y que se determine al mismo acto de pintar y/o dibujar como Transtornar el Subyectil, tomando prestada dicha expresión de Antonin ARTAUD.

Importa sobremanera reparar en seguida que Transtornar se escribe en el infinitivo, con to que queda indecidible la función del Subyectil, pues ha hecho patente Jacques LACAN que la voz infinitiva es la propia voz del fantasma inconsciente y remite al circuito de la pulsión, cuya característica más notable es el intercambio de los lugares del sujeto y del objeto.

Ni el sujeto ni objeto por serlos ambos, el Subyectil desplaza las fronteras del sujeto y del objeto para dejar que pinten 'en él' más bien que 'sobre él' las Cosas de la pintura y del dibujo.

Transtornar el Subyectil formula luego, y deja que se entiendan de un modo un tanto 